\title{
Un gigante de la Infectología Mundial ha muerto: Dr. Merle A. Sande, MACP, FIDSA
}

\author{
A gigant in Infectious Diseases has died: Merle A. Sande, MACP, FIDSA.
}

$\mathrm{M}$ erle A. Sande fue sin duda alguna, uno de los infectólogos contemporáneos más notables y su muerte nos conmueve. Me parece que una breve reseña de su vida y logros es importante para las actuales y futuras generaciones.

Nació el 2 de septiembre de 1939, de padre de ascendencia noruega. Efectuó sus estudios de Medicina en la Washington State University y luego se especializó en Infectología en el New York Hospital/Cornell Medical Center.

Inició su carrera en la Fuerza Aérea y luego se mudó a la Universidad de Virginia como staff, evolucionando en su carrera académica en forma muy rápida, hasta llegar a Profesor de Medicina y Subdirector del Departamento de Medicina. En 1980, aceptó el cargo de jefe de Medicina del San Francisco General Hospital y de Subdirector del Departamento de Medicina de la Universidad de California-San Francisco (UCSF).

En estas circunstancias, se inició el reconocimiento de una nueva enfermedad infecciosa, descrita en Los Angeles y Nueva York, pero que en ese momento comprometía a más de 40 pacientes hospitalizados en el San Francisco General Hospital. Desde ese momento, el Dr. Sande emprende con toda su energía el estudio de esta nueva patología, constituyéndose él y su grupo, como referentes mundiales en el estudio y manejo de los pacientes con VIH/SIDA.

Fue coautor de las primeras guías de control de la infección por VIH, co-editor del primer libro de manejo del SIDA (actualmente en su novena edición), transformándose en uno de los líderes de opinión en este campo.

Fue electo Presidente de la Sociedad

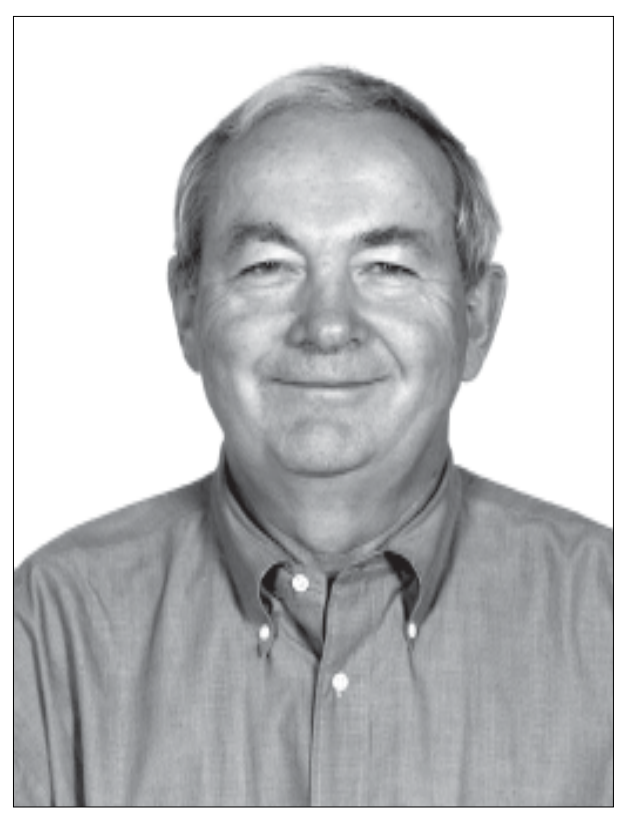

Americana de Infectología (IDSA) y en ese período inició contactos con la Universidad Makerere de Kampala, Uganda, realizando estudios de SIDA bajo el patrocinio de la Rockefeller Foundation.

En 1996 se traslada a Salt Lake City como Jefe del Departamento de Medicina, manteniendo sus contactos académicos con Uganda, lo que lo lleva al desarrollo de una de las más notables iniciativas en el campo de la colaboración internacional en Infectología: el Instituto de Enfermedades Infecciosas en Kampala, con el objeto de entrenar personal de salud para el apropiado tratamiento de los miles de pacientes en el continente.

Fundó y fue el Presidente de la Academic Alliance Foundation (AAF) y co-director de Academic Alliance for AIDS Care. Estas instituciones reclutan médicos americanos y europeos para servir como docentes a miles de médicos y otros profesionales de la salud africanos, lo que ha permitido la formación de más de dos mil personas de 26 países africanos. Cada una de ellas, a su vez, ha entrenado a nuevo personal de salud en el área.

Nuestro país se benefició con un par de visitas, la primera, en el Panamericano de Infectología en Viña en 1993 y luego, como invitado representante del American College of Physicians, en el año 2004.

Los asistentes al congreso anual de la IDSA nunca olvidaremos su extraordinaria capacidad docente, en especial, la presentación y discusión de casos clínicos, que de alguna manera han permeado hacia nuestros eventos.

Su natural simpatía y preocupación por la Medicina Interna e Infectología a nivel global lo hizo un gran aliado de nosotros en ambos campos.

La última etapa de su vida la vivió en Seattle, donde se radicó el año 2005. Poco después se le diagnosticó un mieloma muy agresivo, que finalmente lo llevó a la muerte el 14 de noviembre de 2007.

La comunidad médica y especialmente infectológica internacional, ha perdido un gran maestro y, en lo personal, un gran amigo.

Guillermo Acuña L. FIDSA.

Editor Emérito

Revista Chilena de Infectología Comité de Asuntos Internacionales Sociedad Chilena de Infectología 